Chapter 8

\title{
Current Use of Thalamic Vim \\ Stimulation in Treating \\ Parkinson's Disease
}

\author{
Naoki Tani, Ryoma Morigaki, Ryuji Kaji and \\ Satoshi Goto
}

Additional information is available at the end of the chapter

http://dx.doi.org/10.5772/57105

\section{Introduction}

Recent advances in neuroimaging and neurosurgical techniques provide a growing body of evidence suggesting that deep brain stimulation (DBS) is a powerful and safe therapeutic option for medically intractable Parkinson's disease (PD). For more than half a century, the thalamic ventrolateral (VL) nucleus has been an anatomical target for stereotaxy in treating movement disorders that include PD. It plays a pivotal role in the basal gangliathalamo-cortical circuit that is associated with motor brain functions. The entire output of the basal ganglia is directed to the motor cortex via the VL nucleus where the cerebellar and pallidal afferents terminate predominantly in the ventralis intermedius (Vim) nucleus and ventralis oralis (Vo) nucleus, respectively. In accordance with the general concept that the cerebellothalamic fiber connections participate in tremor genesis, thalamic Vim DBS is now used in the treatment of a wide variety of tremor subtypes with different etiologies. Indeed, thalamic Vim DBS can exert a striking therapeutic impact on tremor-dominant PD that exhibits better clinical prognoses and slower disease progression with less cognitive decline as compared to akinesia/rigidity-dominant PD. In patients with tremor-dominant $\mathrm{PD}$, tremor suppression can be achieved irrespective of age, disease duration, or baseline disease severity. Based on recent advances in the understanding of the pathophysiology of tremor-dominant PD, this review introduces the current use of thalamic Vim stimulation in treating patients with PD. 


\section{Surgical anatomy}

The thalamic VL nucleus comprises 2 major functional territories [1-3]. Neurons in the VL thalamus that respond to voluntary movements are located largely within the Vo [4-6], and neurons that respond to kinesthetic/passive movements about a joint are mainly contained within the Vim [5, 7]. The pallidothalamic inhibitory afferents terminate preferentially in the ipsilateral Vo nucleus, with an anterior-to-posterior gradient of terminal densities through the VL nucleus. In contrast, the cerebellothalamic excitatory afferents terminate predominantly in the contralateral Vim nucleus, creating a posterior-to-anterior gradient of terminal densities through the VL nucleus [8-10]. Moreover, a somatotopic arrangement, i.e., a medial-to-lateral distribution of facial-, forelimb-, and hindlimb-receptive fields, also exists in the VL thalamic nucleus [11-14].

The cerebellothalamic pathway plays a role in the fine spatial and temporal tuning of coordinated movements, as well as in the learning and retention of new motor skills. Thus, functional interference might also be achieved in deep cerebellar nuclei and affect activities in the striatum and cerebral cortices via the VL nucleus, thereby affecting ongoing and intended movements [15-17].

\section{Pathophysiology of parkinsonian tremor}

The clinical heterogeneity of PD is well recognized, and patients can often be divided into tremor-dominant and akinesia/rigidity-dominant subgroups. Accumulating evidence suggests that akinesia/rigidity and tremor may be associated with functional impairments of different motor circuits. Striatal dopamine depletion and dysfunction of the basal ganglia seem to be more important in akinesia/rigidity than in tremor. It is generally thought that tremor is primarily related to the cerebello-thalamo-cortical pathway, while akinesia/rigidity is rooted in the basal ganglia-thalamo-cortical pathway. Recent results from clinicopathological, electrophysiological, and neuroimaging studies on patients with PD are discussed in the following sections.

\subsection{Clinicopathological study}

Although post-mortem studies are limited, patients with tremor-dominant PD appear to progress slowly despite a poorer therapeutic response to levodopa. A statistical analysis performed using the Unified Parkinson's Disease Rating Scale (UPDRS) showed that the motor score for tremor is independent of the scores for other motor symptoms in patients with PD [18]. Rajput et al. [19] reported that patients with tremor-dominant PD showed slower disease progression and lower incidence of dementia than did patients with akinesia/rigiditydominant PD.

Patients with tremor-dominant PD have milder cell loss in the substantia nigra pars compacta and in the locus coeruleus than do patients with non-tremor PD [20]. This suggests that patients 
with tremor-dominant PD have less dopaminergic dysfunction than do patients with nontremor PD. On the other hand, patients with tremor-dominant PD have considerably more cell loss in the retrorubral area of the midbrain [21]. The retrorubral area could produce tremor via its dopaminergic projection to the pallidum. Further, Selikhova et al. [22] reported that patients with the non-tremor subtype had more severe cortical Lewy body pathology and were more likely to develop dementia.

\subsection{Positron emission tomography (PET) and single photon emission computed tomography (SPECT)}

SPECT using Iodine-123 fluoropropyl-carbomethoxy-3 ( $\left[{ }^{123} \mathrm{I}\right] \mathrm{FP}-\mathrm{CIT}$ SPECT) targets the dopamine transporter and is used to determine ongoing loss of dopaminergic neurons in patients with PD [23-25]. [ ${ }^{123}$ I]FP-CIT SPECT shows that patients with tremor-dominant PD had less striatal dopamine depletion than do patients with non-tremor PD [26-28].

The metabolic rate of glucose measured using $\left({ }^{18} \mathrm{~F}\right)$ fluoro-2-deoxy-D-glucose PET (FDG-PET) is known as a marker of integrated local synaptic activities and is sensitive to direct neuronal and synaptic damage and to the functional changes in synaptic activity distant from the primary site of pathology [29]. Using FDG-PET, Mure et al. [30] identified and validated that the PD tremor-related pattern is characterized by covarying metabolic increases in the cerebellum, motor cortex, and putamen. This network correlates specifically with clinical tremor ratings, but not with akinesia/rigidity. In patients with PD tremor, high-frequency stimulation of the Vim nucleus reduces regional metabolism and cerebral blood flow (CBF) in the ipsilateral sensorimotor cortex and contralateral dorsal cerebellar nucleus [30-33], and increases both measures in the Vim nucleus ipsilateral to the stimulation site [30, 34-37]. It should be noted that changes in CBF may not reflect the direct effects of DBS but rather may reflect sensory feedback from changes in motor activity [38].
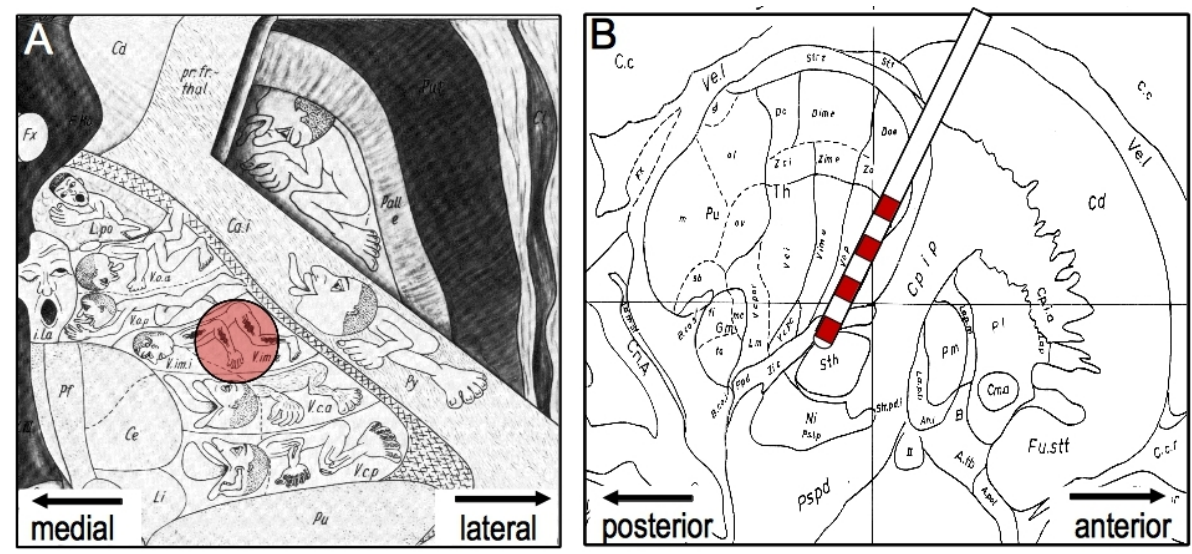

Figure 1. Schematic representations of the stereotactic targets for Vim-DBS on the axial (A) and sagittal (B) planes. The DBS lead implanted into the Vim nucleus is also shown in (B). 


\subsection{Functional magnetic resonance imaging (fMRI)}

Intrinsic blood oxygen consumption detected by fMRI is correlated with low-frequency electrical amplitude fluctuations [64]. Patients with PD show increased overall activity in networks coupled to the primary motor cortex and cerebellum, and reduced functional connections in the supplementary motor area, dorsolateral prefrontal area, and putamen [65]. A recent study with simultaneous fMRI and EMG recording shows that the basal ganglia are transiently activated at the onset of tremor episodes, whereas tremor amplitude-related activity correlates with the cerebello-thalamo-cortical circuit [26]. The patients with tremordominant PD had increased functional connectivity between the basal ganglia and the cerebello-thalamo-cortical circuit.

\subsection{Magnetoencephalography (MEG)}

PD symptoms are related to alterations of oscillatory activity within the basal ganglia. Such pathologically increased oscillations have been demonstrated at several frequencies [56, 57]. In particular, those below $70 \mathrm{~Hz}$ have been shown to be antikinetic [56]. More specifically, oscillations at 4 to $12 \mathrm{~Hz}$ have been related to the origin of tremor symptoms in patients with PD [58]. Double tremor oscillations in the $\beta$ range are not coherent with simultaneously recorded tremors [59-61]. However, a strong coherence in the $\beta$ range is observed in the primary motor cortex, supplementary motor cortex, premotor cortex, diencephalon, and contralateral cerebellum [58]. Interestingly, this coupling can be successfully reduced by dopamine replacement therapy $[62,63]$. These data indicate that PD resting tremor is associated with synchronous oscillatory coupling in a cerebello-thalamo-cortical loop and cortical motor and sensory areas contralateral to the tremor hand [58].

\subsection{Cell recordings}

So-called "kinesthetic" cells receive afferent inputs from muscle spindles and respond to passive joint movements. These cells are located just anterior to the nucleus ventralis caudalis (VC), which receives tactile sensory inputs [39, 40]. Percheron et al. [8] postulated that the kinesthetic zone is located in the latero-ventral part of the Vim nucleus, a region that sends a majority of its axons to the motor cortex. Vitek et al. [13] reported that in a monkey model of PD produced using 1-methyl-4 phenyl-1,2,3,6-tetrahydropyridine (MPTP), the kinesthetic zone expands anteriorly into regions that contain the active movement-related neurons. Kiss et al. [41] reported that in patients with tremor, there is an anterior expansion in the representation of the kinesthetic neurons without a change in their receptive field sizes. They suggested that tremor activates receptors responsive to deep sensations and, to a lesser degree, superficial sensations. Thus, repetitive tremor activities could result in a gradual increase in the synaptic efficacy of somatosensory inputs to kinesthetic neurons. Cells that respond to both somatosensory inputs and active movements are referred to as "combined" cells [42,43] and have been identified only in patients with movement disorders.

Cells in the VL thalamic nucleus that demonstrate a discharge pattern with burst frequencies similar to that of tremor are called "tremor cells" [44, 45]. In a monkey model of resting tremor produced by a lesion of the ventral tegmentum, thalamic activity related to tremor frequency is unchanged following the interruption of sensory inputs [46, 47]. This finding has led to the 
hypothesis that the tremor cells may represent a central pacemaker for generating tremor, independent of sensory feedback $[46,48]$. Tremor cells are reportedly located in the Vim nucleus and Vo complex [43, 49,50]. The distribution of tremor cells is important for thalamic surgery, because tremor has been successfully treated when the radiofrequency lesion was centered within the cluster of tremor cells $[39,51,52]$. However, recent studies show that tremor cells are widely distributed in the Vim, Vo, and VC nuclei, and that they show no apparent differences in proportion within each nucleus [50]. These findings suggest that the ideal surgical target might not be determined by microelectrode recordings of tremor cells alone [49, 53]. The number of tremor cells in patients with PD is much higher than that in patients with other movement disorders, such as essential tremor (ET) and multiple sclerosis. This may play a role in the better surgical outcomes seen in patients with PD [50]. Based on their experiences, Katayama et al. [53] postulated that tremor cells might play a predominant role in the lateral portion of the Vim nucleus, an area that provides the most significant control of PD-associated tremor, in accordance with previous reports [54, 55].

\subsection{Local field potentials (LFPs)}

DBS procedures enable intraoperative micro-/macrorecordings and postoperative macrorecordings. Local field potentials (LFPs) can be recorded via macro- as well as microrecordings [66]. The oscillatory activity in the $\beta$ frequency range has clinical relevance to movement disorders. It is widely distributed throughout the motor system and is desynchronized by voluntary movement in both the Vim and subthalamic nucleus (STN) [67-69]. Levodopa and high-frequency STN stimulation reduce $\beta$ band LFP oscillations. This reduction positively correlates with an improvement of akinesia and rigidity, but not with a decrease of tremor [70-72], and the $\beta$ range STN stimulation causes further impairment of movement in patients with PD [73-76]. The $\alpha$ range oscillations in patients with tremor-dominant PD show finely segregated muscle-specific subloops that strongly correlate with the tremor-affected muscles, and tremor suppression can be achieved using STN-DBS in areas with pronounced $\alpha$ oscillations $[77,78]$. Given that basal ganglia $\beta$ oscillation correlates with rigidity and akinesia and $\alpha$ oscillation correlates with tremor, these findings further suggest a differential pathophysiology between akinesia-rigidity and tremor.

In summary, the pathophysiological studies on parkinsonian tremor indicate that resting tremor may result from a pathological interaction between the basal ganglia and the cerebellothalamo-cortical circuit. Tremor generation in the cerebello-thalamo-cortical circuit is likely triggered by activity in the basal ganglia.

\section{Thalamic Vim DBS}

\subsection{Surgical procedures}

The Vim DBS procedure is divided into the following five stages: (i) stereotactic imaging; (ii) thalamic mapping; (iii) electrode implantation; (iv) receiver of pulse generator implantation; and (v) programming. We perform the two successive steps of the procedure in the same operative session. The first step involves fixation of the stereotactic frame, stereotactic imaging, 
and placement of the thalamic electrode after application of local anesthesia. In the second step, the thalamic electrode is connected to the pulse generator while the patient is under general anesthesia. The intercommissural line-based coordinates for the tentative target in the thalamic Vim are determined $12 \mathrm{~mm}$ lateral to the midline, $5 \mathrm{~mm}$ anterior to the posterior commissure, and on the intercommissural line. In the operating room, a precoronal burr hole is placed $3 \mathrm{~cm}$ lateral to the midline, and a guiding cannula is inserted stereotactically. A quadripolar DBS electrode (Model 3387; Medtronic) is advanced directly through the guiding cannula. The characteristics of the tremor are assessed before, during, and immediately after the insertion of the electrode. Improvement of tremor at the time of insertion of the lead (the "microthalamotomy-like effect") is considered to indicate good positioning of the electrode. Thresholds for both intrinsic and extrinsic evoked responses are analyzed directly via the implanted electrode with a screening device (Model 3625; Medtronic). When a satisfactory electrode position has been achieved, the stylet of the lead and the guiding cannula are carefully removed. The lead is fixed to the cranium with the burr hole ring and cap. General anesthesia is induced while the stereotactic head frame is removed. The pulse generator is implanted in a subcutaneous infraclavicular pouch after being connected to the DBS electrode with a subcutaneous extension wire. In most patients, an Activa SC implantable pulse generator (Medtronic) is used.

The pulse generator can be programmed immediately after surgery. If a prolonged microthalamotomy-like effect is present, the pulse generator is programmed at the time of reappearance of the tremor. Routine postoperative CT scans are performed to rule out hemorrhage. Patients are instructed on how to switch their device on and off using a handheld magnet, and told to turn their device off at night when possible to maximize battery life. Some teams do not connect the pulse generator immediately and use this period to repeat some external stimulation to confirm that the stimulation improves tremor without side effects. This period can also be used to perform a brain MRI to check the electrode location and possible lesion. Many radiologists prefer this to be done before pulse generator implantation for safety reasons.

\subsection{Programming challenges}

The optimal stimulating parameters are determined using monopolar or bipolar stimulation. The easiest way to screen the parameters is to study each contact one after the other: the contact studied is programmed as the cathode, and the case is programmed as the anode. For example, first a constant pulse width of $90 \mu$ s and a constant frequency of $160 \mathrm{~Hz}$ are selected. Then the voltage is progressively increased to find the threshold for symptom suppression without adverse effects, using the contact(s) that gives the best effect. Best results are usually obtained at a pulse frequency of $130-185 \mathrm{~Hz}$ (no lower than $100 \mathrm{~Hz}$ ), pulse width of $60-90 \mu \mathrm{s}$, and amplitude of 1.5-3.6 V.

If this screening does not reveal parameters to control tremor, other combinations can be tried. The pulse width and frequency can be increased. Stimulating more than one contact at the same time and using bipolar stimulation can also be tried. Bipolar stimulation is particularly useful if limiting side effects are obtained with a low voltage before reaching the threshold to 
stop tremor. If these measures are still not helpful, the position of the electrode can be checked using MRI or CT, and re-implantation can be discussed if necessary.

\subsection{Mechanism of action}

Similarities in the effectiveness of thalamic DBS and thalamotomy have led investigators to suggest that DBS acts as a reversible lesion of the thalamus, but the mechanism of action of thalamic DBS is yet unclear. With respect to tremor suppression, 4 different hypotheses of Vim DBS have been proposed: (1) conduction block - this hypothesis is supported by the fact that Vim thalamotomy has similar effects to Vim DBS [83]; (2) activation of inhibitory axon terminals that synapse onto and inhibit projection neurons [93]; (3) superimposition of continuous stimuli onto rhythmically oscillating subcortical-cortical loops [94]; and (4) inhibition of neuronal activity near the stimulation site while activating axonal elements that leave the target structure [95]. Recent reports have shown that during high-frequency stimulation, glutamate and adenosine are increased [96-99], and this elevated glutamate release could excite local interneurons, thereby increasing the production of inhibitory neurotransmitters (e.g., GABA and glycine) and resulting in a decrease in the firing rates of projection neurons [99].

\subsection{Therapeutic impacts}

Before the levodopa era, severe tremor was a main indication for surgery [79]. In the 1960s, thousands of patients with PD throughout the world received a thalamotomy [80] or other procedures such as pallidotomy, campotomy, or pedunculotomy [81]. During this period, it was observed that the high-frequency stimulation used for targeting during lesioning of the thalamus significantly reduced tremor [82]. In the 1980s, Benabid et al. demonstrated that DBS of the Vim significantly reduced tremor, and they have treated more than 100 patients with thalamic DBS [83-85]. Several studies have demonstrated that DBS of the thalamus has comparable control of tremor with fewer side effects than does thalamotomy. Vim DBS is highly beneficial for tremor control, but ineffective for the other disabling features of PD, including akinesia, rigidity, and gait and postural disturbances. Benabid et al. [85] showed that chronic Vim stimulation is highly effective for tremor in a group of 117 tremor patients; over $85 \%$ of patients had a very good or excellent response with little or no tremor evident in the contralateral arm. With a double-blind multicenter study to assess the efficacy of unilateral Vim DBS against placebo, Koller et al. [86] have shown an $80 \%$ reduction in contralateral arm tremor in 24 patients with PD tremor and 29 patients with ET with Vim DBS at the 1-year follow-up.

With respect to the long-term efficacy of Vim DBS, Schuurman et al. [87] reported that $88 \%$ of patients showed complete or nearly complete tremor suppression after a mean follow-up period of 5 years. Hariz et al. [88] reported 38 patients with PD who received Vim DBS with a follow-up period of 6 years. The long-term follow-up of Vim DBS revealed effective control of tremor 6 years postoperatively, while axial symptoms worsened. The initial improvement in activities of daily living (ADL) scores at the 1-year follow-up disappeared after 6 years. Hariz et al. [89] showed significant increases in stimulation parameters for up to 1 year; however, 
after the 1-year stimulation, the parameters seemed to stabilize. By contrast, Kumar et al. [90] reported that it was necessary to increase the current intensity over time to control tremor. This increase in amplitude is undesirable, as it often causes paresthesia and cerebellar adverse effects $[83,91]$. During the follow-up, some tolerance (necessity to gradually increase the voltage to control tremor) and a rebound effect (tremor much worse than before when the stimulator is switched off) can develop [86, 89]. This affects an action tremor more frequently. Switching off the stimulator at night can sometimes limit the tolerance effect. Recurrence of tremor is seen in $\sim 5 \%$ of patients several weeks or years after surgery [83, 92].

\subsection{Adverse events}

The stimulation-induced side effects of Vim DBS are reversible, and usually mild and acceptable. Incidences of stimulation-related complications reported at long-term (greater than 5 years) follow-up include paresthesia (4-38\%), dysarthria (3-36\%), dystonia/hypertonia (3$16 \%)$, gait disturbance (11-16\%), balance disturbance $(5 \%)$, and cognitive dysfunction $(2 \%)$. Among these adverse effects, non-adjustable and long-lasting complications include dysarthria $(10-27 \%)$, paresthesia $(16 \%)$, gait disturbance $(7 \%)$, dystonia $(5 \%)$, upper limb ataxia (3$4 \%)$, and disequilibrium (3-4\%) [88, 100, 101]. Pahwa et al. [101] described occurrences of persistent complications, including dysarthria, disequilibrium, and gait disturbance, after bilateral stimulation, even when the stimulus parameters were optimized.

The incidence of infection appears to be $0-11 \%$ during the early follow-up periods and 0 $8 \%$ throughout the postoperative course $[87,88,100]$. Hardware failures are occasionally found in the stimulator $(0-3 \%)$, the DBS lead $(0-8 \%)$, or the cable $(0-3 \%)$; skin erosion $(0-$ $4 \%)$ and hematoma requiring evacuation of the stimulator $(0-3 \%)$ have also been reported $[87,88,100]$.

\section{Conclusions}

Vim DBS is an appropriate first-line treatment for medically intractable tremor in patients with PD. Although its therapeutic effects on ADL outcome decreases gradually after the surgery, long-term tremor suppression remains stable. We suggest that Vim DBS is useful for patients with tremor-dominant PD, who manifest slow progression of disease and a good response of non-tremor PD symptoms to dopaminergic therapy.

\section{Acknowledgements}

This work was supported in part by the Grants from the Ministry of Education, Culture, Sports, Science and Technology of Japan (grant-in-aid for Scientific Research, 23500428; 21390269; 23659458; 24390223). 


\section{Author details}

Naoki Tani ${ }^{1}$, Ryoma Morigaki ${ }^{2}$, Ryuji Kaji ${ }^{3}$ and Satoshi Goto ${ }^{2}$

*Address all correspondence to: sgoto@clin.med.tokushima-u.ac.jp

1 Department of Neurosurgery, Otemae Hospital, Osaka, Japan

2 Department of Motor Neuroscience and Neurotherapeutics, Institute of Health Biosciences, Graduate School of Medical Sciences, University of Tokushima, Tokushima, Japan

3 Department of Clinical Neuroscience, Institute of Health Biosciences, Graduate School of Medical Sciences, University of Tokushima, Tokushima, Japan

\section{References}

[1] Asanuma, C.; Thach, WT. \& Jones EG. (1983). Distribution of cerebellar terminations and their relation to other afferent terminations in the ventral lateral thalamic region of the monkey. Brain Res. 286 (3): 237-265.

[2] Kultas-Ilinsky, K. \& Ilinsky IA. (1991). Fine structure of the ventral lateral nucleus (VL) of the Macaca mulatta thalamus: cell types and synaptology. J Comp Neurol. 314 (2): 319-349.

[3] Ilinsky, IA. \& Kultas-Ilinsky, K. (2002). Motor thalamic circuits in primates with emphasis on the area targeted in treatment of movement disorders. Mov Disord. 17 (Suppl 3): S9-14.

[4] Hassler, R. Anatomy of the thalamus. In: Schaltenbrand G, Bailer, P., editor. An introduction to Stereotaxis With an Atlas of the Human Brain. Stuttgart: Thieme; 1959. p. 230-290.

[5] Krack, P.; Dostrovsky, J.; Ilinsky, I.; Kultas-Ilinsky, K.; Lenz, F.; Lozano, A. \& Vitek, J. (2002). Surgery of the motor thalamus: problems with the present nomenclatures. Mov Disord. 17 (Suppl 3): S2-S8.

[6] Lenz, FA.; Jaeger, CJ.; Seike, MS.; Lin, YC. \& Reich, SG. (2002). Single-neuron analysis of human thalamus in patients with intention tremor and other clinical signs of cerebellar disease. J Neurophysiol. 87 (4): 2084-94.

[7] Ohye, C.; Maeda, T. \& Narabayashi, H. (1976). Physiologically defined VIM nucleus. Its special reference to control of tremor. Appl Neurophysiol. 39 (3-4): 285-295.

[8] Percheron, G.; Francois, C.; Talbi, B.; Yelnik, J. \& Fenelon, G. (1996). The primate motor thalamus. Brain research Brain research reviews. 22 (2): 93-181. 
[9] Sakai, ST.; Inase, M. \& Tanji, J. (1996). Comparison of cerebellothalamic and pallidothalamic projections in the monkey (Macaca fuscata): a double anterograde labeling study. J Comp Neurol. 368 (2): 215-228.

[10] Gallay, MN.; Jeanmonod, D.; Liu, J. \& Morel, A. (2008). Human pallidothalamic and cerebellothalamic tracts: anatomical basis for functional stereotactic neurosurgery. Brain Struct Funct. 212 (6): 443-463.

[11] Strick, PL. (1976). Activity of ventrolateral thalamic neurons during arm movement. Journal of neurophysiology. 39 (5): 1032-1044.

[12] Asanuma, C.; Thach, WR.; \& Jones, EG. (1983). Anatomical evidence for segregated focal groupings of efferent cells and their terminal ramifications in the cerebellothalamic pathway of the monkey. Brain Res. 286 (3): 267-297.

[13] Vitek, JL.; Ashe, J.; DeLong, MR. \& Alexander, GE. (1994). Physiologic properties and somatotopic organization of the primate motor thalamus. J Neurophysiol. 71 (4): 1498-1513.

[14] Vitek, JL.; Ashe, J,; DeLong, MR. \& Kaneoke, Y. (1996). Microstimulation of primate motor thalamus: somatotopic organization and differential distribution of evoked motor responses among subnuclei. J Neurophysiol. 75(6): 2486-95.

[15] Rispal-Padel, L.; Harnois, C. \& Troiani, D. (1987). Converging cerebellofugal inputs to the thalamus. I. Mapping of monosynaptic field potentials in the ventrolateral nucleus of the thalamus. Exp Brain Res. 68 (1): 47-58.

[16] Rispal-Padel, L.; Troiani, D. \& Harnois, C. (1987). Converging cerebellofugal inputs to the thalamus. II. Analysis and topography of thalamic EPSPs induced by convergent monosynaptic interpositus and dentate inputs. Exp Brain Res. 68 (1): 59-72.

[17] Craig, AD. (2008). Retrograde analyses of spinothalamic projections in the macaque monkey: input to the ventral lateral nucleus. J Comp Neurol. 508 (2): 315-328.

[18] Stochl, J.; Boomsma, A.; Ruzicka, E.; Brozova, H. \& Blahus, P. (2008). On the structure of motor symptoms of Parkinson's disease. Mov Disord. 23 (9): 1307-1312.

[19] Rajput, AH.; Voll, A.; Rajput, ML.; Robinson, CA. \& Rajput, A. (2009). Course in Parkinson disease subtypes: A 39-year clinicopathologic study. Neurology. 73 (3): 206-212.

[20] Paulus, W. \& Jellinger, K. (1991). The neuropathologic basis of different clinical subgroups of Parkinson's disease. J Neuropathol Exp Neurol. 50 (6): 743-755.

[21] Hirsch, EC.; Mouatt, A.; Faucheux, B.; Bonnet, AM.; Javoy-Agid, F.; Graybiel, AM. \& Agid, Y. (1992). Dopamine, tremor, and Parkinson's disease. Lancet. 340 (8811): 125-126. 
[22] Selikhova, M.; Williams, DR.; Kempster, PA.; Holton, JL.; Revesz, T. \& Lees, AJ. (2009). A clinico-pathological study of subtypes in Parkinson's disease. Brain. 132 (Pt 11): 2947-2957.

[23] Kaufman, MJ. \& Madras, BK. (1991). Severe depletion of cocaine recognition sites associated with the dopamine transporter in Parkinson's-diseased striatum. Synapse. 9 (1): 43-49.

[24] Niznik, HB.; Fogel, EF.; Fassos, FF. \& Seeman, P. (1991). The dopamine transporter is absent in parkinsonian putamen and reduced in the caudate nucleus. J Neurochem. 56 (1): 192-198.

[25] Seibyl, JP.; Marek, K.; Sheff, K.; Zoghbi, S.; Baldwin, RM.; Charney, DS., van Dyck, CH. \& Innis, RB. (1998). Iodine-123-beta-CIT and iodine-123-FPCIT SPECT measurement of dopamine transporters in healthy subjects and Parkinson's patients. J Nucl Med. 39 (9): 1500-1508.

[26] Helmich, RC.; Janssen, MJ.; Oyen, WJ.; Bloem, BR. \& Toni, I. (2011). Pallidal dysfunction drives a cerebellothalamic circuit into Parkinson tremor. Ann Neurol. 69 (2): 269-281.

[27] Rossi C, Frosini D, Volterrani D, De Feo P, Unti E, Nicoletti V, et al. Differences in nigro-striatal impairment in clinical variants of early Parkinson's disease: evidence from a FP-CIT SPECT study. European journal of neurology : the official journal of the European Federation of Neurological Societies. 2010; 17(4): 626-30.

[28] Spiegel J, Hellwig D, Samnick S, Jost W, Mollers MO, Fassbender K, Kirsch, CM. \& Dillmann, U. (2007). Striatal FP-CIT uptake differs in the subtypes of early Parkinson's disease. J Neural Transm. 114 (3): 331-335.

[29] Magistretti, PJ.; Pellerin, L.; Rothman, DL. \& Shulman, RG. (1999). Energy on demand. Science. 283 (5401): 496-497.

[30] Mure, H.; Hirano, S.; Tang, CC.; Isaias, IU.; Antonini, A.; Ma, Y.; Dhawan, V. \& Eidelberg, D. (2011). Parkinson's disease tremor-related metabolic network: characterization, progression, and treatment effects. Neuroimage. 54 (2): 1244-1253.

[31] Parker, F.; Tzourio, N.; Blond, S.; Petit, H. \& Mazoyer, B. (1992). Evidence for a common network of brain structures involved in parkinsonian tremor and voluntary repetitive movement. Brain Res. 584 (1-2): 11-17.

[32] Boecker, H.; Wills, AJ.; Ceballos-Baumann, A.; Samuel, M.; Thomas, DG.; Marsden, CD. \& Brooks, DJ. (1997). Stereotactic thalamotomy in tremor-dominant Parkinson's disease: an H2(15)O PET motor activation study. Ann Neurol. 41 (1): 108-111.

[33] Wielepp, JP.; Burgunder, JM.; Pohle, T.; Ritter, EP.; Kinser, JA. \& Krauss, JK. (2001). Deactivation of thalamocortical activity is responsible for suppression of parkinsonian tremor by thalamic stimulation: a 99mTc-ECD SPECT study. Clin Neurol Neurosurg. 103 (4): 228-231. 
[34] Rezai, AR.; Lozano, AM.; Crawley, AP.; Joy, ML.; Davis, KD.; Kwan, CL.; Dostrovsky, JO.; Tasker, RR. \& Mikulis, DJ. (1999). Thalamic stimulation and functional magnetic resonance imaging: localization of cortical and subcortical activation with implanted electrodes. J Neurosurg. 90 (3): 583-590.

[35] Perlmutter, JS.; Mink, JW.; Bastian, AJ.; Zackowski, K.; Hershey, T.; Miyawaki, E.; Koller, W. \& Videen, TO. (2002). Blood flow responses to deep brain stimulation of thalamus. Neurology. 58 (9): 1388-1394.

[36] Haslinger, B.; Boecker, H.; Buchel, C.; Vesper, J.; Tronnier, VM.; Pfister, R.; Alesch, F.; Moringlane, JR.; Krauss, JK.; Conrad, B.; Schwaiger, M. \& Ceballos-Baumann, AO. (2003). Differential modulation of subcortical target and cortex during deep brain stimulation. Neuroimage. 18 (2): 517-524.

[37] Fukuda M, Barnes A, Simon ES, Holmes A, Dhawan V, Giladi N, Fodstad H, Ma Y, Eidelberg D. (2004). Thalamic stimulation for parkinsonian tremor: correlation between regional cerebral blood flow and physiological tremor characteristics. Neuroimage. 21 (2): 608-615.

[38] Perlmutter, JS. \& Mink, JW. (2006). Deep brain stimulation. Ann Rev Neurosci. 29: 229-257.

[39] Ohye, C. \& Narabayashi, H. (1979). Physiological study of presumed ventralis intermedius neurons in the human thalamus. J Neurosurg. 50 (3): 290-297.

[40] Ohye, C.; Shibazaki, T.; Hirai, T.; Wada, H.; Hirato, M. \& Kawashima, Y. (1989). Further physiological observations on the ventralis intermedius neurons in the human thalamus. J Neurophysiol. 61 (3): 488-500.

[41] Kiss, ZH.; Davis, KD.; Tasker, RR.; Lozano, AM.; Hu, B. \& Dostrovsky, JO. (2003). Kinaesthetic neurons in thalamus of humans with and without tremor. Exp Brain Res. 150 (1): 85-94.

[42] Lenz, FA.; Kwan, HC.; Dostrovsky, JO.; Tasker, RR.; Murphy, JT. \& Lenz, YE. (1990). Single unit analysis of the human ventral thalamic nuclear group. Activity correlated with movement. Brain. 113 ( Pt 6): 1795-1821.

[43] Lenz, FA.; Kwan, HC.; Martin, RL.; Tasker, RR.; Dostrovsky, JO. \& Lenz, YE. (1994). Single unit analysis of the human ventral thalamic nuclear group. Tremor-related activity in functionally identified cells. Brain. 117 ( Pt 3): 531-543.

[44] Lenz, FA.; Tasker, RR.; Kwan, HC.; Schnider, S.; Kwong, R.; Murayama, Y.; Dostrovsky, JO. \& Murphy, JT. (1988). Single unit analysis of the human ventral thalamic nuclear group: correlation of thalamic "tremor cells" with the 3-6 Hz component of parkinsonian tremor. J Neurosci. 8 (3): 754-764.

[45] Ohye, C.; Saito, U.; Fukamachi, A. \& Narabayashi, H. (1974). An analysis of the spontaneous rhythmic and non-rhythmic burst discharges in the human thalamus. J Neurol Sci. 22 (2): 245-259. 
[46] Lamarre, Y. \& Joffroy, A. Experimental tremor in monkey: activity of thalamic and precentral cortical neurons in the absence of peripheral feedback. In: Poirier LJ, Sourkes TI, Bedard P, editors. Adcances in Neurology. New York: Raven Press; 1979. p. 109-122.

[47] Ohye, C.; Bouchard, R.; Larochelle, L.; Bedard, P.; Boucher, R.; Raphy, B. \& Poirier, LJ. (1970). Effect of dorsal rhizotomy on postural tremor in the monkey. Exp Brain Res. 10 (2): 140-150.

[48] Lee, RG. \& Stein, RB. (1981). Resetting of tremor by mechanical perturbations: a comparison of essential tremor and parkinsonian tremor. Ann Neurol. 10 (6): 523-531.

[49] Kobayashi, K.; Katayama, Y.; Kasai, M.; Oshima, H.; Fukaya, C. \& Yamamoto, T. (2003). Localization of thalamic cells with tremor-frequency activity in Parkinson's disease and essential tremor. Acta Neurochir. 87 (Suppl): 137-139.

[50] Brodkey, JA.; Tasker, RR.; Hamani, C.; McAndrews, MP.; Dostrovsky, JO. \& Lozano, AM. (2004). Tremor cells in the human thalamus: differences among neurological disorders. J Neurosurg. 101 (1): 43-47.

[51] Hirai, T.; Shibazaki, T.; Nakajima, H.; Imai, S. \& Ohye, C. (1979). Minimal effective lesion in the stereotactic treatment of tremor. Appl Neurophysiol. 42 (5): 307-308.

[52] Nagaseki, Y.; Shibazaki, T.; Hirai, T.; Kawashima, Y.; Hirato, M.; Wada, H.; Wada, H.; Miyazaki, M. \& Ohye, C. (1986). Long-term follow-up results of selective VIMthalamotomy. J Neurosurg. 65 (3): 296-302.

[53] Katayama, Y.; Kano, T.; Kobayashi, K.; Oshima, H.; Fukaya, C. \& Yamamoto, T. (2005). Difference in surgical strategies between thalamotomy and thalamic deep brain stimulation for tremor control. Journal of neurology. 252 (Suppl 4): IV17-IV22.

[54] Hariz, MI. \& Hirabayashi, H. (1997). Is there a relationship between size and site of the stereotactic lesion and symptomatic results of pallidotomy and thalamotomy? Stereotact Funct Neurosurg. 69 (1-4 Pt 2): 28-45.

[55] Atkinson, JD.; Collins, DL.; Bertrand, G.; Peters, TM.; Pike, GB. \& Sadikot, AF. (2002). Optimal location of thalamotomy lesions for tremor associated with Parkinson disease: a probabilistic analysis based on postoperative magnetic resonance imaging and an integrated digital atlas. J Neurosurg. 96 (5): 854-866.

[56] Schnitzler, A. \& Gross, J. (2005). Normal and pathological oscillatory communication in the brain. Nat Rev Neurosci. 6 (4): 285-296.

[57] Hutchison, WD.; Dostrovsky, JO.; Walters, JR.; Courtemanche, R.; Boraud, T.; Goldberg, J. \& Brown, P. (2004). Neuronal oscillations in the basal ganglia and movement disorders: evidence from whole animal and human recordings. J Neurosci. 24 (42): 9240-9243. 
[58] Timmermann, L.; Gross, J.; Dirks, M.; Volkmann, J.; Freund, HJ. \& Schnitzler, A. (2003). The cerebral oscillatory network of parkinsonian resting tremor. Brain. $126(\mathrm{Pt}$ 1): $199-212$.

[59] Raz, A.; Vaadia, E. \& Bergman, H. (2000). Firing patterns and correlations of spontaneous discharge of pallidal neurons in the normal and the tremulous 1-methyl-4-phenyl-1,2,3,6-tetrahydropyridine vervet model of parkinsonism. J Neurosci. 20 (22): 8559-8571.

[60] Lemstra, AW.; Verhagen-Metman, L.; Lee, JI.; Dougherty, PM. \& Lenz, FA. (1999). Tremor-frequency (3-6 Hz) activity in the sensorimotor arm representation of the internal segment of the globus pallidus in patients with Parkinson's disease. Neurosci Lett. 267 (2): 1291-32.

[61] Hurtado, JM.; Rubchinsky, LL.; Sigvardt, KA.; Wheelock, VL. \& Pappas, CT. (2005). Temporal evolution of oscillations and synchrony in GPi/muscle pairs in Parkinson's disease. J Neurophysiol. 93 (3): 1569-1584.

[62] Salenius, S.; Avikainen, S.; Kaakkola, S.; Hari, R. \& Brown, P. (2002). Defective cortical drive to muscle in Parkinson's disease and its improvement with levodopa. Brain. 125 (Pt 3): 491-500.

[63] Pollok, B.; Makhloufi, H.; Butz, M.; Gross, J.; Timmermann, L.; Wojtecki, L. \& Schnitzler, A. (2009). Levodopa affects functional brain networks in Parkinsonian resting tremor. Mov Disord. 24 (1): 91-98.

[64] Logothetis, NK. \& Wandell, BA. (2004). Interpreting the BOLD signal. Annu Rev Physiol. 66: 735-769.

[65] Wu, T.; Chan, P. \& Hallett, M. (2010). Effective connectivity of neural networks in automatic movements in Parkinson's disease. Neuroimage. 49 (3): 2581-2587.

[66] Brown, P. (2003). Oscillatory nature of human basal ganglia activity: relationship to the pathophysiology of Parkinson's disease. Mov Disord. 18 (4): 357-363.

[67] Klostermann, F.; Nikulin, VV.; Kuhn, AA.; Marzinzik, F.; Wahl, M.; Pogosyan, A.; Kupsch, A.; Schneider, GH.; Brown, P. \& Curio, G. (2007). Task-related differential dynamics of EEG alpha- and beta-band synchronization in cortico-basal motor structures. Eur J Neurosci. 25 (5): 1604-1615.

[68] Paradiso, G.; Cunic, D.; Saint-Cyr, JA.; Hoque, T.; Lozano, AM.; Lang, AE. \& Chen, R. (2004). Involvement of human thalamus in the preparation of self-paced movement. Brain. 127 (Pt 12): 2717-2731.

[69] Kühn, AA.; Williams, D.; Kupsch, A.; Limousin, P.; Hariz, M.; Schneider, GH.; Yarrow, K. \& Brown, P. (2004). Event-related beta desynchronization in human subthalamic nucleus correlates with motor performance. Brain. 127 (Pt 4): 735-746. 
[70] Bronte-Stewart, H.; Barberini, C.; Koop, MM.; Hill, BC.; Henderson, JM. \& Wingeier, B. (2009). The STN beta-band profile in Parkinson's disease is stationary and shows prolonged attenuation after deep brain stimulation. Exp Neurol. 215 (1): 20-28.

[71] Ray, NJ.; Jenkinson, N.; Wang, S.; Holland, P.; Brittain, JS.; Joint, C.; Stein, JF. \& Aziz, T. (2008). Local field potential beta activity in the subthalamic nucleus of patients with Parkinson's disease is associated with improvements in bradykinesia after dopamine and deep brain stimulation. Exp Neurol. 213 (1): 108-113.

[72] Kühn, AA.; Kupsch, A.; Schneider, GH. \& Brown, P. (2006). Reduction in subthalamic 8-35 Hz oscillatory activity correlates with clinical improvement in Parkinson's disease. Eur J Neurosci. 23 (7): 1956-1960.

[73] Brown, P.; Oliviero, A.; Mazzone, P.; Insola, A.: Tonali, P. \& Di Lazzaro, V. (2001). Dopamine dependency of oscillations between subthalamic nucleus and pallidum in Parkinson's disease. J Neurosci. 21 (3): 1033-1038.

[74] Fogelson, N.; Kuhn, AA.; Silberstein, P.; Limousin, PD.; Hariz, M.; Trottenberg, T.; Kupsch, A. \& Brown, P. (2005). Frequency dependent effects of subthalamic nucleus stimulation in Parkinson's disease. Neurosci Lett. 382 (1-2): 5-9.

[75] Chen, CC.; Litvak, V.; Gilbertson, T.; Kuhn, A.; Lu, CS.; Lee, ST.; Tsai, CH.; Tisch, S.; Limousin, P.; Hariz, M. \& Brown, P. (2007). Excessive synchronization of basal ganglia neurons at $20 \mathrm{~Hz}$ slows movement in Parkinson's disease. Exp Neurol. 205 (1): 214-221.

[76] Eusebio, A.; Chen, CC.; Lu, CS.; Lee, ST.; Tsai, CH.; Limousin, P.; Hariz, M. \& Brown, P. (2008). Effects of low-frequency stimulation of the subthalamic nucleus on movement in Parkinson's disease. Exp Neurol. 209 (1): 125-130.

[77] Reck, C.; Florin, E.; Wojtecki, L.; Krause, H.; Groiss, S.; Voges, J.; Maarouf, M.; Sturm, V.; Schnitzler, A. \& Timmermann, L. (2009). Characterisation of tremor-associated local field potentials in the subthalamic nucleus in Parkinson's disease. Eur J Neurosci. 29 (3): 599-612.

[78] Reck, C.; Himmel, M.; Florin, E.; Maarouf, M.; Sturm, V.; Wojtecki, L.; Schnitzler, A.; Fink, GR. \& Timmermann, L. (2010). Coherence analysis of local field potentials in the subthalamic nucleus: differences in parkinsonian rest and postural tremor. Eur J Neurosci. 32 (7): 1202-1214.

[79] Gildenberg, PL. History of Movement Disorder Surgery. In: Lozano A, editor. Movement Disorder Surgery Prog Neurol Surg. Basel: Karger; 2000. p. 1-20.

[80] Kelly PJ. Stereotactic thalamotomies. In: Koller W, Pulson G, editors. Therapy of Parkinson's Disease. 2nd ed. New York: Mecel Dekker; 1995. p. 331-351.

[81] Guridi, J. \& Lozano, AM. (1997). A brief history of pallidotomy. Neurosurgery. 41(5): 1169-80. 
[82] Hassler, R.; Riechert, T.; Mundinger, F.; Umbach, W. \& Ganglberger, JA. (1960). Physiological observations in stereotaxic operations in extrapyramidal motor disturbances. Brain. 83: 337-350.

[83] Benabid, AL.; Pollak, P.; Gao, D.; Hoffmann, D.; Limousin, P.; Gay, E.; Payen, I. \& Benazzouz, A. (1996). Chronic electrical stimulation of the ventralis intermedius nucleus of the thalamus as a treatment of movement disorders. J Neurosurg. 84 (2): 203-214.

[84] Benabid, AL.; Pollak, P.; Gervason, C.; Hoffmann, D.; Gao, DM.; Hommel, M.; Perret, JE. \& de Rougemont, J. (1991). Long-term suppression of tremor by chronic stimulation of the ventral intermediate thalamic nucleus. Lancet. 337 (8738): 403-406.

[85] Pollak, P.; Benabid, AL.; Limousin, P. \& Benazzouz, A. (1997). Chronic intracerebral stimulation in Parkinson's disease. Adv Neurol. 74: 213-20.

[86] Koller, W.; Pahwa, R.; Busenbark, K.; Hubble, J.; Wilkinson, S.; Lang, A.; Tuite, P.; Sime, E.; Lozano, A.; Hauser, R.; Malapira, T.; Smith, D.; Tarsy, D.; Miyawaki, E.; Norregaard, T.; Kormos, T. \& Olanow, CW. (1997). High-frequency unilateral thalamic stimulation in the treatment of essential and parkinsonian tremor. Ann Neurol. 42 (3): 292-299.

[87] Schuurman, PR.; Bosch, DA.; Merkus, MP. \& Speelman, JD. (2008). Long-term follow-up of thalamic stimulation versus thalamotomy for tremor suppression. Mov Disord. 23 (8): 1146-1153.

[88] Hariz, MI.; Krack, P.; Alesch, F.; Augustinsson, LE.; Bosch, A.; Ekberg, L.; Johansson, F.; Johnels, B.; Meyerson, BA.; N'Guyen, JP.; Pinter, M.; Pollak, P.; von Raison, F.; Rehncrona, S.; Speelman, JD.; Sydow, O. \& Benabid, AL. (2008). Multicentre European study of thalamic stimulation for parkinsonian tremor: a 6 year follow-up. J Neurol Neurosurg Psychiatry. 79 (6): 694-699.

[89] Hariz, MI.; Shamsgovara, P.; Johansson, F.; Hariz, G. \& Fodstad, H. (1999). Tolerance and tremor rebound following long-term chronic thalamic stimulation for Parkinsonian and essential tremor. Stereotact Funct Neurosurg. 72 (2-4): 208-218.

[90] Kumar, K.; Kelly, M. \& Toth, C. (1999). Deep brain stimulation of the ventral intermediate nucleus of the thalamus for control of tremors in Parkinson's disease and essential tremor. Stereotact Funct Neurosurg. 72 (1): 47-61.

[91] Yamamoto, T.; Katayama, Y.; Kano, T.; Kobayashi, K.; Oshima, H. \& Fukaya, C. (2004). Deep brain stimulation for the treatment of parkinsonian, essential, and poststroke tremor: a suitable stimulation method and changes in effective stimulation intensity. J Neurosurg. 101 (2): 201-209.

[92] Tasker, RR. (1998). Deep brain stimulation is preferable to thalamotomy for tremor suppression. Surg Neurol. 49 (2): 145-153. 
[93] Wu, YR.; Levy, R.; Ashby, P.; Tasker, RR. \& Dostrovsky, JO. (2001). Does stimulation of the GPi control dyskinesia by activating inhibitory axons? Mov Disord. 16 (2): 208-216.

[94] Montgomery, EBJr. \& Baker, KB. (2000). Mechanisms of deep brain stimulation and future technical developments. Neurol Res. ogical research. 22 (3): 259-266.

[95] Vitek, JL. (2002). Mechanisms of deep brain stimulation: excitation or inhibition. Mov Disord. 17 (Suppl 3): S69-S72.

[96] Anderson, TR.; Hu, B.; Iremonger, K. \& Kiss, ZH. (2006). Selective attenuation of afferent synaptic transmission as a mechanism of thalamic deep brain stimulation-induced tremor arrest. J Neurosci. 26 (3): 841-850.

[97] Anderson, T.; Hu, B.; Pittman, Q. \& Kiss, ZH. (2004). Mechanisms of deep brain stimulation: an intracellular study in rat thalamus. J Physiol. 559 (Pt 1): 301-313.

[98] Bekar, L.; Libionka, W.; Tian, GF.; Xu, Q.; Torres, A.; Wang, X.; Lovatt, D.; Williams, E.; Takano, T.; Schnermann, J.; Bakos, R. \& Nedergaard, M. (2008). Adenosine is crucial for deep brain stimulation-mediated attenuation of tremor. Nat Med. 14 (1): 75-80.

[99] Tawfik, VL.; Chang, SY.; Hitti, FL.; Roberts, DW.; Leiter, JC.; Jovanovic, S. \& Lee, KH. (2010). Deep brain stimulation results in local glutamate and adenosine release: investigation into the role of astrocytes. Neurosurgery. 67 (2): 367-375.

[100] Rehncrona, S.; Johnels, B.; Widner, H.; Tornqvist, AL.; Hariz, M. \& Sydow, O. (2003). Long-term efficacy of thalamic deep brain stimulation for tremor: double-blind assessments. Mov Disord. 18 (2): 163-170.

[101] Pahwa, R.; Lyons, KE.; Wilkinson, SB.; Simpson, RKJr.; Ondo, WG.; Tarsy, D.; Norregaard, T.; Hubble, JP.; Smith, DA.; Hauser, RA. \& Jankovic J. (2006). Long-term evaluation of deep brain stimulation of the thalamus. J Neurosurg. 104 (4): 506-512. 
